\title{
The Impact of Traffic-Induced Bridge Vibration on Rapid Repairing High-Performance Concrete for Bridge Deck Pavement Repairs
}

\author{
Wei Wang, 1,2,3 Shuo Liu, ${ }^{1,4}$ Qizhi Wang, Wei Yuan, ${ }^{1}$ Mingzhang Chen,' \\ Xiaotian Hao, ${ }^{1,3}$ Shuai Ma, ${ }^{1,3}$ and Xuanyu Liang ${ }^{1,3}$ \\ ${ }^{1}$ School of Civil Engineering, Shijiazhuang Tiedao University, Shijiazhuang 050043, China \\ ${ }^{2}$ Hebei Province Key Laboratory of Large Structure Health Diagnosis and Control, Shijiazhuang Tiedao University, \\ Shijiazhuang 050043, China \\ ${ }^{3}$ Collaborative Innovation Center of Large Infrastructure Disaster Prevention and Mitigation, Shijiazhuang Tiedao University, \\ Shijiazhuang 050043, China \\ ${ }^{4}$ School of Communications and Transportation, Shijiazhuang Tiedao University, Shijiazhuang 050043, China
}

Correspondence should be addressed to Wei Yuan; weiyuanac@163.com

Received 1 May 2014; Revised 30 October 2014; Accepted 31 October 2014; Published 19 November 2014

Academic Editor: Aiguo Xu

Copyright (C) 2014 Wei Wang et al. This is an open access article distributed under the Creative Commons Attribution License, which permits unrestricted use, distribution, and reproduction in any medium, provided the original work is properly cited.

Based on forced vibration tests for high-performance concrete (HPC), the influence of bridge vibration induced by traveling vehicle on compressive strength and durability of HPC has been studied. It is concluded that $1 \mathrm{~d}$ and $2 \mathrm{~d}$ compressive strength of HPC decreased significantly, and the maximum reduction rate is $9.1 \%$, while $28 \mathrm{~d}$ compressive strength of HPC had a slight lower with a $3 \%$ maximal drop under the action of two simple harmonic vibrations with $2 \mathrm{~Hz}, 3 \mathrm{~mm}$ amplitude, and $4 \mathrm{~Hz}, 3 \mathrm{~mm}$ amplitude. Moreover, the vibration had a slight effect on the compressive strength of HPC when the simple harmonic vibration had $4 \mathrm{~Hz}$ and $1 \mathrm{~mm}$ amplitude; it is indicated that the amplitude exerts a more prominent influence on the earlier compressive strength with the comparison of the frequency. In addition, the impact of simple harmonic vibration on durability of HPC can be ignored; this shows the self-healing function of concrete resulting from later hydration reaction. Thus, the research achievements mentioned above can contribute to learning the laws by which bridge vibration affects the properties of concrete and provide technical support for the design and construction of the bridge deck pavement maintenance.

\section{Introduction}

Due to rapid economic development in China, traffic volumes have significantly increased. Traffic loads on highways and bridges have continued to increase, which has caused significant damage to many bridge deck pavements and generated numerous heavy maintenance projects. During the process of highway bridge deck pavement renovation, bridge deck pavement repair projects should be performed without complete bridge closures ( $1 / 4$ of the bridge is opened to traffic) to maintain efficient traffic flows. Because the repairing concrete endures constant impact from trafficinduced bridge vibration during the pouring, setting, and hardening processes, the impact of vibration on the mechanical performance and durability of repairing HPC for bridge deck pavement deserves our attention.

A concrete vibration test stand with a $48 \mathrm{~Hz}$ and an amplitude range of $0.5 \mathrm{~mm}-0.8 \mathrm{~mm}$ as the vibration source, one set of specimens was selected every $30 \mathrm{~min}$ from $90 \mathrm{~min}$ to $330 \mathrm{~min}$ after the concrete was poured to impose $30 \mathrm{~s}$ of vibration and to investigate the variation in the concrete's strength at $3 \mathrm{~d}, 7 \mathrm{~d}$, and $28 \mathrm{~d}$. The results showed that vibration prior to hardening can improve the compressive strength of concrete, whereas vibration after hardening can reduce the compressive strength of concrete [1]. Papers adopted a cement mortar vibration test stand as the vibration source. Under 
the vibration conditions of $1 \mathrm{~Hz}$ and $4 \mathrm{~Hz}$ frequencies with $3 \mathrm{~mm}$ and $5 \mathrm{~mm}$ amplitudes, $30 \mathrm{~min}$ vibrations were imposed $1 \mathrm{~h}, 2.5 \mathrm{~h}, 3.5 \mathrm{~h}, 4.5 \mathrm{~h}, 6 \mathrm{~h}$, and $8 \mathrm{~h}$ after pouring to measure the splitting tensile strengths of the specimens. The results showed that a vibration with a $5 \mathrm{~mm}$ amplitude imposed between initial hardening and final hardening reduced the tensile strength of the concrete [2,3]. A rapping sieve is used as a vibration source and imposed a two-dimensional plane vibration condition with a lateral $(3.68 \mathrm{~Hz}, 20 \mathrm{~mm}$ amplitude) and vertical $(2.45 \mathrm{~Hz}, 4 \mathrm{~mm}$ amplitude) vibration. Vibrations that extended $10 \mathrm{~min}$ for every $60 \mathrm{~min}$ at intervals of $0-7 \mathrm{~h}, 7-14 \mathrm{~h}$, and $14-24 \mathrm{~h}$ were imposed after pouring to determine the concrete's antiperturbation using an ultrasound method. The results showed that the concrete experienced an insignificant change in wave velocity under vibration conditions from $0-7 \mathrm{~h}$ and $14-24 \mathrm{~h}$; however, the concrete strength under the vibration conditions decreased by an average of 2.2 MPa from 7 to $14 \mathrm{~h}$ [4-6]. Dunham et al. adopted a vibration test bed (VP5101, Syntron Corporation) as the vibration source. Under the condition of $60 \mathrm{~Hz}$ and peak vibration velocity ranges of $50-100 \mathrm{~mm} / \mathrm{s}$ and $200-$ $300 \mathrm{~mm} / \mathrm{s}, 2 \mathrm{~min}$ vibrations were imposed at $2 \mathrm{~h}, 3.5 \mathrm{~h}, 4.5 \mathrm{~h}$, $5 \mathrm{~h}$, and $6 \mathrm{~h}$ after pouring. The splitting tensile strength and compressive strength of the specimen were measured for different concrete ages. The experimental results showed that vibration did not generate a significant impact on concrete strength [7]. In addition, papers conducted studies on the impact of vibration loading on concrete performance. Their findings concluded that vibration has an insignificant impact on the late-stage strength of concrete [8-13].

These studies evaluated the impact of vibration on the concrete hardening process. However, several shortcomings in the previous studies have been identified: (1) trafficinduced bridge vibrations comprise a sustained, complex, and random process, because the vibration sources selected in the previous studies only provided singular vibration parameters and they cannot precisely simulate bridge vibration; (2) the impact from bridge vibration persists for a sustained interval during concrete hardening; in the previous studies, the vibration periods were too short to stimulate vibration; (3) during the process of highway bridge pavement renovation, the repairing concrete should achieve a high early-stage strength to ensure that the bridge can be opened to traffic as soon as possible, but the previous studies on the earlystage strength of concrete under the impact of vibration are limited; (4) in recent years, the durability of concrete has attracted considerable attention and the repairing concrete should possess satisfactory durability to improve its service life; however, few studies have focused on the impact of vibration on concrete durability. Therefore, to accurately analyze the impact of vibration on high-performance repair HPC for conditions in which the bridge is opened to traffic, this study used an electromagnetic vibration test bed with continuous vibration capability as artificial vibration source and configured different vibration parameters to simulate traffic-induced bridge vibration. The impact of vibration on the compressive strengths of different ages of rapid repairing high-performance concrete (HPC) $(1 \mathrm{~d}, 2 \mathrm{~d}, 5 \mathrm{~d}, 7 \mathrm{~d}$, and $28 \mathrm{~d}$ ) and the $56 \mathrm{~d}$ durability of rapid repairing HPC were also explored in different concrete hardening processes. The experimental results provided technical support for the repairing design and construction of bridge deck pavement without bridge closures and the importance of opening a bridge to traffic as soon as possible and ensuring superior quality of the repairing concrete.

\section{Experimental Design}

One of the key issues of the laboratory test for studying the influence of bridge vibration on the strength and durability of concrete is to choose reasonable simulation parameters to simulate bridge vibration. However, bridge vibration is a complex and random process that is impacted by various factors, such as vehicle loading size, speed, bridge surface flatness, and bridge structure. Therefore the accurate assessment of traffic-induced bridge vibration parameters is difficult and impractical. To simplify the vibration form, the simple harmonic vibration provided by an electromagnetic experiment test stand was adopted to simulate bridge vibration. Bridge vibration parameters were determined by combining the bridge vibration test results and the results of previous studies. Concrete hardening is a complex and gradually changing process. To study the impact of vibration on the performance of bridge deck pavement repairing HPC, this complex process should be divided into different phases based on the characteristics of concrete hardening, which can facilitate the analysis of the perturbation conditions for different concrete hardening phases using a targeted approach.

2.1. Determination of Vibration Parameters. To acquire reasonable simulation parameters from bridge vibration induced by traveling vehicle, the 891-4 type vibration pickup, QY2 inclinometer, and G01NET type data acquisition instrument were adopted to perform vibration tests on the JingZhang Highway K120+685 overpass. As shown in Figure 1, the bridge cross portfolio of the $\mathrm{K} 120+685$ overpass is $4 \times 38 \mathrm{~m}$; the upper section consists of a steel-concrete composite structure, and the lower section consists of a column pier. The vibration test entails measurements of the bridge's horizontal, lateral, and vertical vibration parameters under four conditions during which the bridge was open to traffic: prior to carving the bridge deck pavement, after carving the bridge deck pavement, after carving the bridge deck pavement and supporting the bottom section of the bridge, and after pouring the bridge deck pavement repairing HPC. In the vibration test, three 891-4 vibration sensors were installed at the middle of the main span to measure the vibration acceleration, velocity, displacement, and main vibration frequency of the bridge, as shown in Figure 1(a). Five QY-2 inclinometers were also installed on the main span to measure the dynamic deflection of the bridge, as shown in Figure 1(b). From the measurements, we derived the following results: for different bridge conditions during which the bridge is open to traffic, the vertical vibration is the maximum vibration, the frequency ranges from 2.5 to $5.5 \mathrm{~Hz}$, and the vertical deflection ranges from 0.3 to $3 \mathrm{~mm}$. 


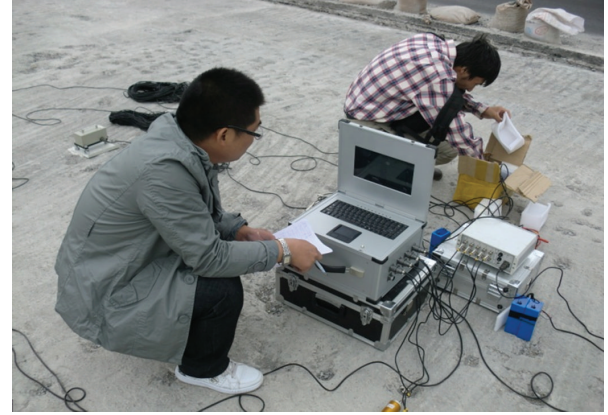

(a) Sensor installation layout

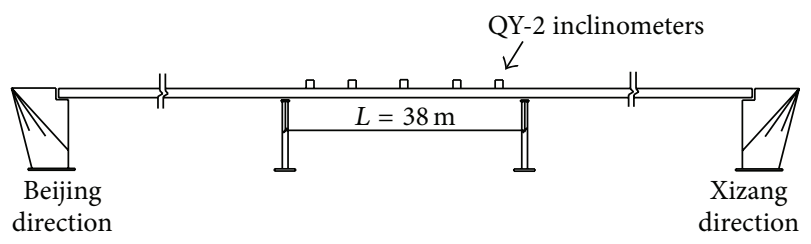

(b) Inclinometer installation layout

FIGURE 1: Bridge vibration measurement and test chart.

By investigating 224 different types of bridges, the Swiss Federal Research Laboratory determined that a bridge's actual measured natural frequency was $f=1.23-14 \mathrm{~Hz}$ with an average natural frequency of $f_{m}=3.62 \mathrm{~Hz}$ [14]. By combining the vibration data derived from the vibration test, the following representative vibration parameter combinations were established as experimental vibration parameters for this experiment: a frequency of $2 \mathrm{~Hz}$ with an amplitude of $3 \mathrm{~mm}$, a frequency of $4 \mathrm{~Hz}$ with an amplitude of $1 \mathrm{~mm}$, and a frequency of $4 \mathrm{~Hz}$ with an amplitude of $3 \mathrm{~mm}$. An aircooled electromagnetic vibration test stand was used as the vibration output source, as shown in Figure 2. The maximum displacement peak value for the vibration test stand was $51 \mathrm{~mm}$, and the excitation force ranged from 1 to $70 \mathrm{kN}$.

2.2. Division of Concrete Hardening Process. Based on cement concrete hardening theory [2], few hydration products are generated during the early phase of a cement-water reaction and the attractions among these products are relatively small. As time evolves, $\mathrm{C}-\mathrm{H}-\mathrm{S}$ forms long gel fibers, and a flocculation structure is created from the AFt and other hydration crystals between the cement particles. The cement paste begins to lose plasticity, which initiates the strength of concrete. As various hydrates significantly increase, the void spaces between the cement particles are filled with the hydration product to form an interlocking structure for which the strength continues to improve. As the cement paste loses plasticity, the hardening process begins, and cement forms at the beginning of the hardening phase.

During different hardening phases, concrete exhibits different vibration responses. Prior to the vibration experiment, highway engineering, cement, and concrete, test procedures were followed, and penetration resistance test meters were used to measure the change in the ultimate shear stress of the repairing concrete as a function of time [15].

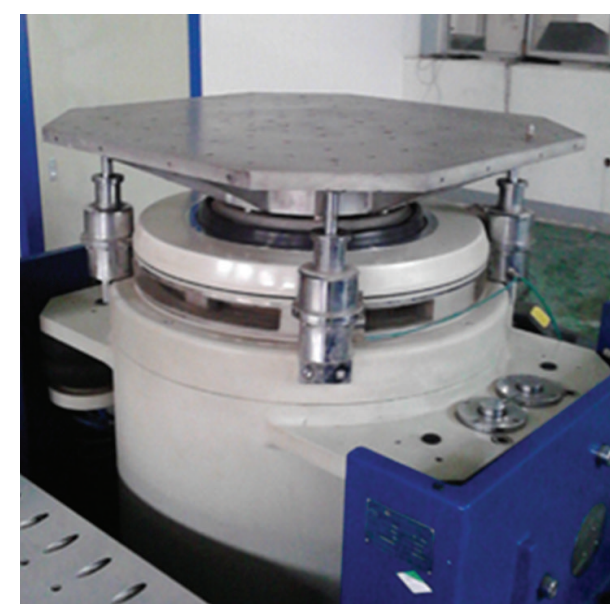

FIGURE 2: Air-cooled electromagnetic vibration test stand.

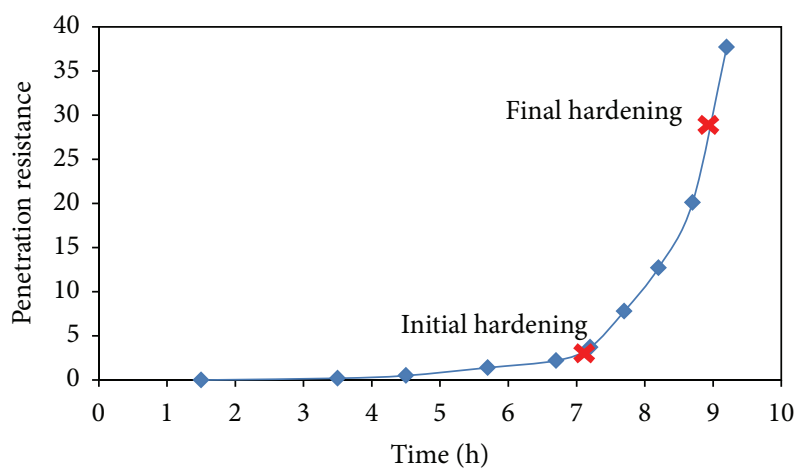

Figure 3: Penetration resistance curve for the concrete sample.

The initial and final hardening times for the rapid repair highperformance concrete on the bridge deck pavement were determined. The curve for the penetration resistance test results is shown in Figure 3. The measurement results show that the initial and final hardening times for the repairing concrete are $7 \mathrm{~h}$ and $9 \mathrm{~h}$. This experiment explored the conditions in which rapid repair high-performance concrete was perturbed during three phases: pouring-initial hardening (0$7 \mathrm{~h}$ ), initial hardening-final hardening (7-9h), and pouringfinal hardening (0-9 h).

2.3. Experimental Groupings. Based on the previously mentioned analysis, three kinds of simple harmonic vibrations with different frequency and amplitude are imposed on the concrete specimens at pouring to the initial hardening phase, initial hardening to final hardening phase, and pouring to the final hardening phase, respectively. And then the compressive strength of the perturbed concrete at $1 \mathrm{~d}, 2 \mathrm{~d}, 5 \mathrm{~d}, 7 \mathrm{~d}$, and $28 \mathrm{~d}$, the electric flux at $56 \mathrm{~d}$, and the freeze-thaw performance at $56 \mathrm{~d}$ were analyzed and compared to study the impact of vibration on the strength and durability of the HPC installed on the bridge deck pavement. The experimental groupings are described in Table 1 . 
TABLE 1: Experimental groupings.

\begin{tabular}{|c|c|c|c|c|c|}
\hline Project & Control specimen/block & $\begin{array}{c}\text { Vibration } \\
\text { parameters }\end{array}$ & $\begin{array}{l}\text { Pouring-initial } \\
\text { hardening }(0-7 \mathrm{~h}) \\
\text { specimen/block }\end{array}$ & $\begin{array}{c}\text { Initial } \\
\text { hardening-final } \\
\text { hardening }(7-9 \mathrm{~h}) \\
\text { specimen/block }\end{array}$ & $\begin{array}{c}\text { Pouring-final } \\
\text { hardening }(0-9 \mathrm{~h}) \\
\text { specimen/block }\end{array}$ \\
\hline \multirow{3}{*}{ Compressive strength } & \multirow{3}{*}{18} & $2 \mathrm{~Hz}, 3 \mathrm{~mm}$ & 18 & 18 & 18 \\
\hline & & $4 \mathrm{~Hz}, 1 \mathrm{~mm}$ & 18 & 18 & 18 \\
\hline & & $4 \mathrm{~Hz}, 3 \mathrm{~mm}$ & 18 & 18 & 18 \\
\hline \multirow{3}{*}{ Freeze-thaw } & \multirow{3}{*}{3} & $2 \mathrm{~Hz}, 3 \mathrm{~mm}$ & 3 & 3 & 3 \\
\hline & & $4 \mathrm{~Hz}, 1 \mathrm{~mm}$ & 3 & 3 & 3 \\
\hline & & $4 \mathrm{~Hz}, 3 \mathrm{~mm}$ & 3 & 3 & 3 \\
\hline \multirow{3}{*}{ Electric flux } & \multirow{3}{*}{3} & $2 \mathrm{~Hz}, 3 \mathrm{~mm}$ & 3 & 3 & 3 \\
\hline & & $4 \mathrm{~Hz}, 1 \mathrm{~mm}$ & 3 & 3 & 3 \\
\hline & & $4 \mathrm{~Hz}, 3 \mathrm{~mm}$ & 3 & 3 & 3 \\
\hline
\end{tabular}

2.4. Experimental Process. From a large number of laboratory experiments that are based on concrete workability and the performance requirement of rapid repair HPC, the following results can be derived regarding the benchmark ratio (mass ratio) of the HPC_cement : fly : slag : silicafume : sand : stone : water : acid water reducing agent: polypropylene fiber $=375: 50: 50: 71: 680: 1115: 155: 6: 1$; water-paste ratio $=0.31$; sand ratio $=0.38$; initial degree of slumping $=200 \mathrm{~mm}$ and $1 \mathrm{~h}$ after initial slumping, the degree of slumping was $180 \mathrm{~mm}$.

The experimental process and procedures to determine the impact of vibration on the strength of HPC are listed below.

(1) Based on the experimental grouping, the HPC samples were installed into test molds with dimensions of $150 \mathrm{~mm} \times 150 \mathrm{~mm} \times 150 \mathrm{~mm}$ after mixing.

(2) The specimens for the pouring-initial hardening and pouring-final hardening phases were divide into two layers and installed on the experimental vibration test stand; each layer placed 18 concrete specimens. In addition, a positioning bolt was tightened to prevent the specimens from shaking, as shown in Figure 4. The initial hardening-final hardening specimens and the control group specimens were installed adjacent to the experimental test stand to maintain identical hardening conditions.

(3) After one kind of vibration parameters was established (e.g., $2 \mathrm{~Hz}, 3 \mathrm{~mm}$ amplitude), the electromagnetic test stand was turned on. After forced vibration with 7 hours was applied to the concrete specimens, the vibration stand was paused, the experimental group for the pouring-initial hardening phase was removed, and the experimental group for the initial hardening-final hardening phase, which had been stored beside the vibration stand, was placed on the test stand. The test stand was turned on for $2 \mathrm{~h}$ of additional vibration and then turned off.

(4) After completing one kind of vibration parameters experiments (e.g., $2 \mathrm{~Hz}, 3 \mathrm{~mm}$ amplitude), all experimental specimens were removed and placed into

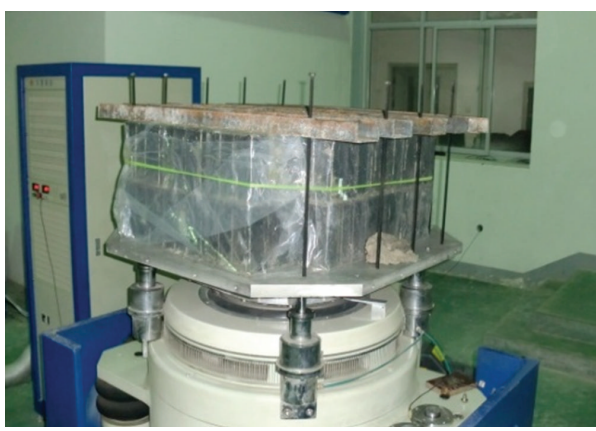

FIGURE 4: Specimen fixation method.

a conservation room for cultivation. The concrete compressive strengths at different concrete ages (i.e., $1 \mathrm{~d}, 2 \mathrm{~d}, 5 \mathrm{~d}, 7 \mathrm{~d}$, and $28 \mathrm{~d}$ ) were measured.

(5) Utilizing this experimental procedure, experiments for measuring the impact of vibration on the mechanical performance of HPC were performed using the remaining two vibration parameter combinations.

For the experiments in which the impact on the durability of HPC was measured, premixed concrete (using the mentioned above experimental grouping methods) was placed into test molds with dimensions of $400 \mathrm{~mm} \times 100 \mathrm{~mm} \times$ $100 \mathrm{~mm}$ to measure the frost resistance of concrete and test molds with dimensions of $\varphi 100 \mathrm{~mm} \times 50 \mathrm{~mm}$ to measure the concrete flux of concrete. With the exception of the steps for measuring the $56 \mathrm{~d}$ frost resistance and electric flux, all experimental methods and steps for studying the impact of vibration on the durability and compressive strength of rapid repairing HPC were identical.

\section{Experimental Results and Mechanism Analysis}

3.1. Experimental Results for Mechanical Performance. A digital display press was used to measure the compressive strengths for various specimen groups; the data results are 
TABLE 2: Compressive strength and rate of change of HPC specimens with vibration parameters of $2 \mathrm{~Hz}$ and $3 \mathrm{~mm}$.

\begin{tabular}{lccccccc}
\hline Age/d & $\begin{array}{c}\text { Control } \\
\text { specimen/MPa }\end{array}$ & $\begin{array}{c}\text { Pouring-initial } \\
\text { hardening/MPa }\end{array}$ & $\begin{array}{c}\text { Changes } \\
\text { proportion/\% }\end{array}$ & $\begin{array}{c}\text { Initial } \\
\text { hardening-final } \\
\text { hardening/MPa }\end{array}$ & $\begin{array}{c}\text { Changes } \\
\text { proportion/\% }\end{array}$ & $\begin{array}{c}\text { Pouring-final } \\
\text { hardening/MPa }\end{array}$ & $\begin{array}{c}\text { Changes } \\
\text { proportion/\% }\end{array}$ \\
\hline 1 & 20.1 & 18.7 & -7.1 & 18.3 & -9.1 & 20.0 & -0.6 \\
2 & 35.2 & 32.9 & -6.5 & 32.3 & -8.2 & 34.0 & -3.4 \\
5 & 46.7 & 46.2 & -1.1 & 46.2 & -1.1 & 44.8 & -4.1 \\
7 & 49.3 & 49.4 & +0.2 & 49.5 & +0.4 & -3.4 & +0.2 \\
28 & 63.0 & 61.4 & -2.5 & 61.1 & -3.0 & 62.1 & -1.4 \\
\hline
\end{tabular}

Note that "+" and "-" represent the decrease and increase of the compressive strength of the HPC specimens, respectively. And the same implication is in the subsequent tables.

TABLE 3: Compressive strength and rate of change of HPC specimens with vibration parameters of $4 \mathrm{~Hz}$ and $3 \mathrm{~mm}$.

\begin{tabular}{lccccccc}
\hline Age/d & $\begin{array}{c}\text { Control } \\
\text { specimen/MPa }\end{array}$ & $\begin{array}{c}\text { Pouring-initial } \\
\text { hardening/MPa }\end{array}$ & $\begin{array}{c}\text { Changes } \\
\text { proportion/\% }\end{array}$ & $\begin{array}{c}\text { Initial } \\
\text { hardening-final } \\
\text { hardening/MPa }\end{array}$ & $\begin{array}{c}\text { Changes } \\
\text { proportion/\% }\end{array}$ & $\begin{array}{c}\text { Pouring-final } \\
\text { hardening/MPa }\end{array}$ & $\begin{array}{c}\text { Changes } \\
\text { proportion/\% }\end{array}$ \\
\hline 1 & 20.1 & 18.7 & -7.0 & 19.0 & -5.6 & 19.5 & -3.1 \\
2 & 35.2 & 33.2 & -5.7 & 33.2 & -5.7 & 34.9 & -0.8 \\
5 & 46.7 & 46.3 & -0.9 & 46.5 & -0.4 & 45.7 & -2.1 \\
7 & 49.3 & 48.7 & -1.2 & 47.3 & -4.1 & 47.9 & -2.8 \\
28 & 63.0 & 64.1 & +1.7 & 61.5 & -2.4 & 62.0 & -1.6 \\
\hline
\end{tabular}

shown in Tables 2,3 , and 4 . The corresponding timestrength change curves are shown in Figures 5, 6, and 7. The experimental results indicate that the compressive strengths for various vibration experiment groups at a HPC age of $28 \mathrm{~d}$ do not significantly differ from the compressive strengths for the still experiment group. To improve the display of the impact rule for early-stage concrete by vibration, Figures 57 do not contain strength experiment data for the $28 \mathrm{~d} \mathrm{HPC}$ age.

As shown in Table 2 and Figure 5, when the specimen experiences vibration with a $2 \mathrm{~Hz}$ and a $3 \mathrm{~mm}$ amplitude during the three phases of pouring-initial hardening, initial hardening-final hardening, and pouring-final hardening, the degree of impact by vibration exhibits similar trends. Compared with the compressive strengths for the still experiment group, compressive strengths of the specimens at $1 \mathrm{~d}$ and $2 \mathrm{~d}$ exhibited a slight reduction and the maximum reduction rate is $9.1 \%$, the compressive strengths at $5 \mathrm{~d}, 7 \mathrm{~d}$, and $28 \mathrm{~d}$ were slightly reduced, and the reduction amplitude also decreased as the age increased and the compressive strengths at $28 \mathrm{~d}$ decreased by $1.4 \% \sim 3 \%$. In addition, the average reduction rate of compressive strength of HPC specimens at $1 \mathrm{~d}$ and $2 \mathrm{~d}$ at pouring-initial hardening phase, initial hardening-final hardening phase, and pouring-final hardening phase is $6.8 \%$, $8.7 \%$, and $2.0 \%$, respectively.

For the specimen that experienced vibration with a $4 \mathrm{~Hz}$ and $3 \mathrm{~mm}$ amplitude, the experimental results showed trends similar to the trends for the specimen that experienced vibration with a $2 \mathrm{~Hz}$ and $3 \mathrm{~mm}$ amplitude, as shown in Table 3 and Figure 6. Compared with the compressive strengths for the still experiment group, the maximum reduction rate for compressive strength of HPC specimens at $1 \mathrm{~d}$ and $2 \mathrm{~d}$ was $7 \%$ and the maximum reduction rate for the $28 \mathrm{~d}$ compressive

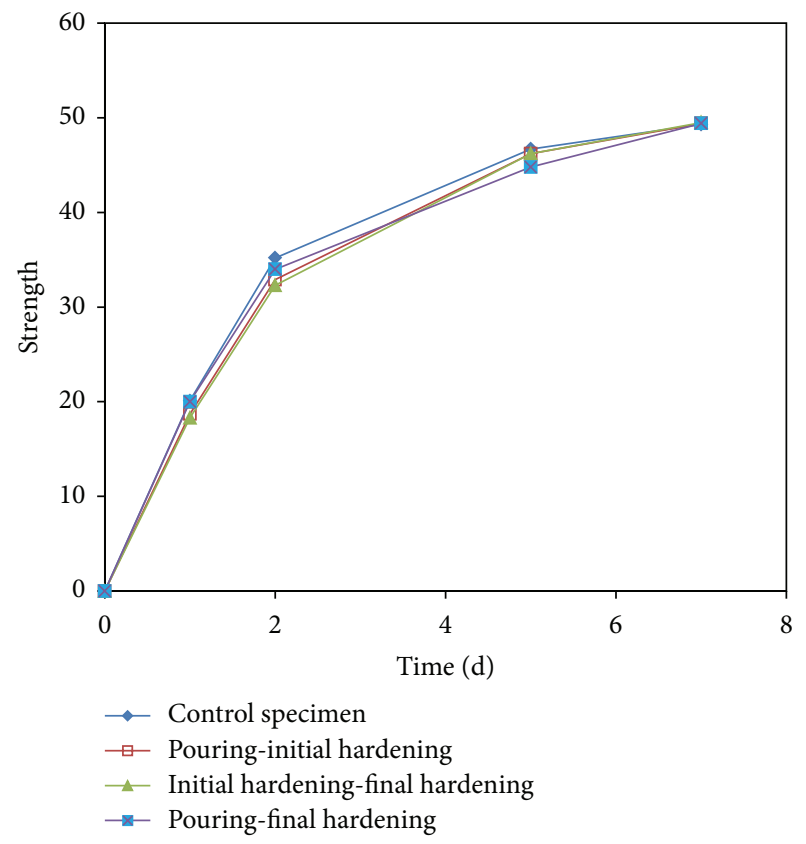

FIGURE 5: Compressive strength and rate of change of HPC specimens with vibration parameters of $2 \mathrm{~Hz}$ and $3 \mathrm{~mm}$.

strength was $2.4 \%$. The average reduction rate of compressive strength of HPC specimens at $1 \mathrm{~d}$ and $2 \mathrm{~d}$ at pouring-initial hardening phase, initial hardening-final hardening phase, and pouring-final hardening phase is $6.4 \%, 5.7 \%$, and $2.0 \%$, respectively.

As shown in Table 4 and Figure 7, the vibration with the $4 \mathrm{~Hz}$ and $1 \mathrm{~mm}$ amplitude had a slight effect on the 
TABLE 4: Compressive strength and rate of change of HPC specimens with vibration parameters of $4 \mathrm{~Hz}$ and $1 \mathrm{~mm}$.

\begin{tabular}{lccccccc}
\hline Age/d & $\begin{array}{c}\text { Control } \\
\text { specimen/MPa }\end{array}$ & $\begin{array}{c}\text { Pouring-initial } \\
\text { hardening/MPa }\end{array}$ & $\begin{array}{c}\text { Changes } \\
\text { proportion/\% }\end{array}$ & $\begin{array}{c}\text { Initial } \\
\text { hardening-final } \\
\text { hardening/MPa }\end{array}$ & $\begin{array}{c}\text { Changes } \\
\text { proportion/\% }\end{array}$ & $\begin{array}{c}\text { Pouring-final } \\
\text { hardening/MPa }\end{array}$ & $\begin{array}{c}\text { Changes } \\
\text { proportion/\% }\end{array}$ \\
\hline 1 & 20.1 & 19.6 & -2.5 & 20.2 & +0.5 & 19.7 & -2.1 \\
2 & 35.2 & 34.2 & -2.8 & 35.6 & +1.1 & 36.0 & +2.3 \\
5 & 46.7 & 44.9 & -3.9 & 46.7 & +0.0 & 48.4 & 48.7 \\
7 & 49.3 & 50.3 & +2.0 & 50.4 & +2.2 & -1.2 & -1.2 \\
28 & 63.0 & 61.2 & -0.29 & 62.4 & -1.0 & 62.3 & -1.1 \\
\hline
\end{tabular}

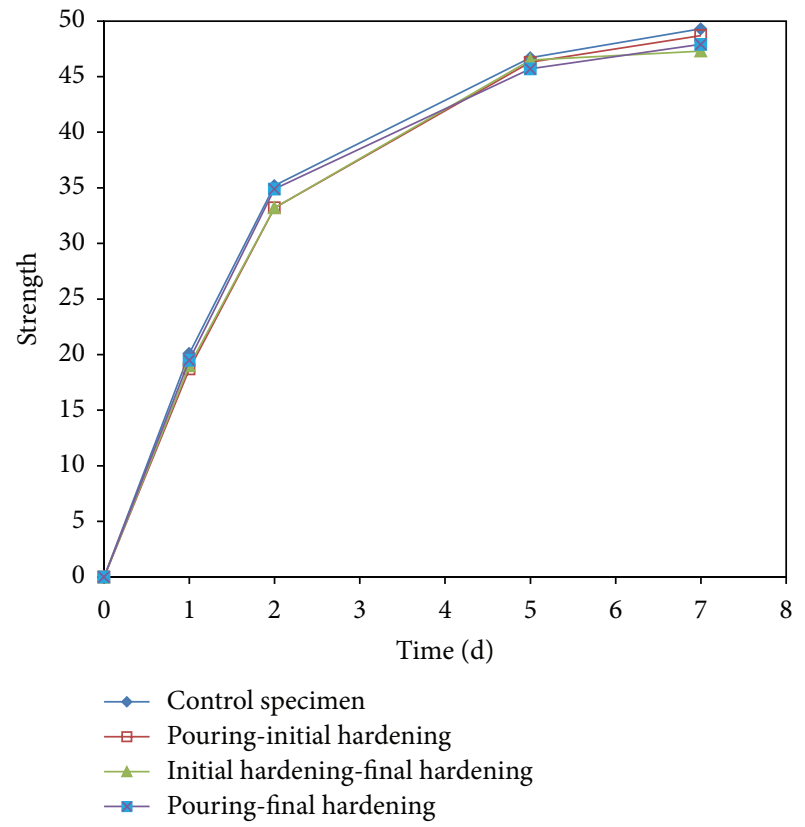

Figure 6: Compressive strength and rate of change of HPC specimens with vibration parameters of $4 \mathrm{~Hz}$ and $3 \mathrm{~mm}$.

compressive strength of the HPC specimens. The $1 \mathrm{~d}$ and $2 \mathrm{~d}$ compressive strengths of the HPC specimens exhibited a change range of $-2.8 \% \sim+2.3 \%$. At $5 \mathrm{~d}, 7 \mathrm{~d}$, and $28 \mathrm{~d}$, the compressive strengths of the HPC specimens exhibited a change range of $-3.9 \% \sim+3.6 \%$.

The impact of vibration on concrete hardening is complex. Currently, no consensus has been formed in international studies about how vibration impacts concrete hardening. This study derived the following analyses based on the experimental results.

(1) The electromagnetic vibration test stand forced the concrete specimen to vibrate and enter an acceleration field that was represented by a sinusoidal curve. The coarse aggregate, fine aggregate, cementitious materials, and water in the concrete exhibited different responses to the acceleration. The vibration caused the coarse aggregate, cementitious materials, and water to separate. Due to the vibration of certain parameters, excessive free water emerged on the surface between the aggregate and the cementitious

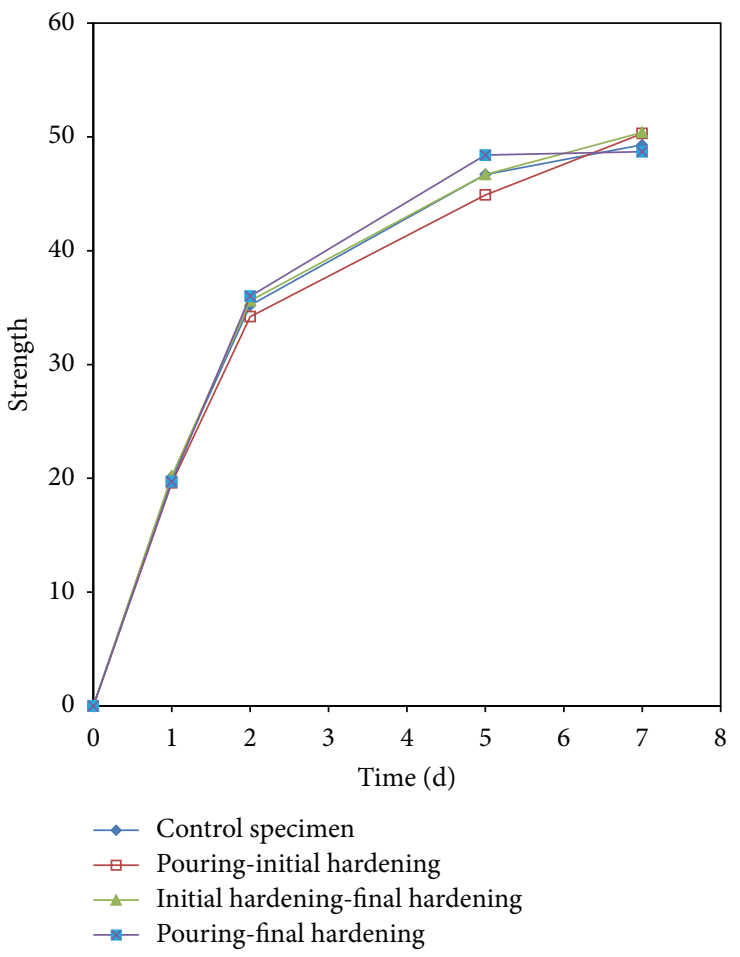

FIgURE 7: Compressive strength and rate of change of HPC specimens with vibration parameters of $4 \mathrm{~Hz}$ and $1 \mathrm{~mm}$.

materials, which slowed the hydration reaction in the concrete. After the vibration stopped, the concrete remained in this hardening condition. However, the above effect is not obvious at the condition of other vibrations. Therefore, compared with the still experiment group, the specimens in the vibration experimental group exhibited a reduced for concrete ages of $1 \mathrm{~d}$ and $2 \mathrm{~d}$, in which the parameters of vibrations are $2 \mathrm{~Hz}, 3 \mathrm{~mm}$ amplitude, and $4 \mathrm{~Hz}, 3 \mathrm{~mm}$ amplitude. However, the effect is not obvious at the vibration with $4 \mathrm{~Hz}$ and $1 \mathrm{~mm}$ amplitude.

(2) Although vibration can weaken the interface between the aggregates and the cementitious materials, vibration does not cause distinct segregation of HPC aggregate, as demonstrated by the cross-sections of the HPC specimens (Figure 8); this finding may be attributed to the addition of polypropylene fibers in 


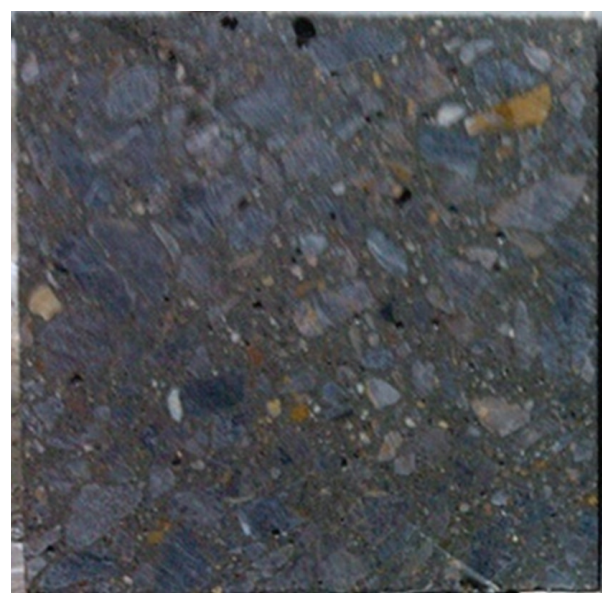

(a) Still control group

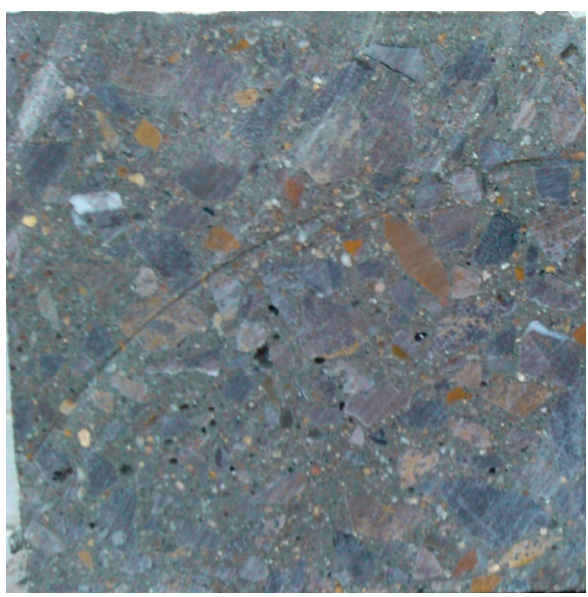

(b) Vibration experimental group

Figure 8: Cross-section of specimen.

TABLE 5: Electric flux and change ratio $(C)$.

\begin{tabular}{|c|c|c|c|c|c|c|c|}
\hline $\begin{array}{l}\text { Vibration } \\
\text { parameters }\end{array}$ & $\begin{array}{c}\text { Control } \\
\text { specimen }\end{array}$ & $\begin{array}{l}\text { Pouring-initial } \\
\text { hardening }\end{array}$ & $\begin{array}{c}\text { Changes } \\
\text { proportion/\% }\end{array}$ & $\begin{array}{c}\text { Initial } \\
\text { hardening-final } \\
\text { hardening }\end{array}$ & $\begin{array}{c}\text { Changes } \\
\text { proportion/\% }\end{array}$ & $\begin{array}{l}\text { Pouring-final } \\
\text { hardening }\end{array}$ & $\begin{array}{c}\text { Changes } \\
\text { proportion/\% }\end{array}$ \\
\hline $\begin{array}{l}F=2 \mathrm{~Hz} \\
H=3 \mathrm{~mm}\end{array}$ & 333.0 & 349.9 & +5.1 & 346.1 & +3.9 & 340.5 & +2.3 \\
\hline $\begin{array}{l}F=4 \mathrm{~Hz} \\
H=3 \mathrm{~mm}\end{array}$ & 333.0 & 335.4 & +0.7 & 345.3 & +3.7 & 348.2 & +4.6 \\
\hline $\begin{array}{l}F=4 \mathrm{~Hz} \\
H=1 \mathrm{~mm}\end{array}$ & 333.0 & 328.8 & -1.3 & 351.8 & +5.6 & 337.8 & +1.4 \\
\hline
\end{tabular}

the HPC. Tens of millions of polypropylene fibers, which interconnect and bond to form an amorphous supporting system, were incorporated into the concrete. Polypropylene fibers simultaneously dissipated the concrete's shrink energy, which is associated with a high tensile strength and a low elastic modulus, onto the polypropylene fibers to prevent the expansion of the existing fragile components of the concrete to enhance the internal continuity of the material and to alleviate sinking of the aggregate sinking and the reduced strength caused by vibration. As the concrete age increased, the concrete continued to undergo a hydration reaction, and its fragile components were enhanced, which reflect the self-repairing performance of the concrete. Compared with the still experiment group, these analyses reasonably explain the phenomenon for which the compressive strengths of the specimen under the impact of vibration at $5 \mathrm{~d}$, $7 \mathrm{~d}$, and $28 \mathrm{~d}$ experienced minimal change and the amplitude gradually reduced as the age increased.

3.2. Experimental Results for Durability Performance. The experimental results obtained from the $56 \mathrm{~d}$ electric flux experiment and the $56 \mathrm{~d} 300$-interval freeze-thaw cycle test are shown in Tables 5 and 6 . The corresponding electric flux histogram is shown in Figure 9.

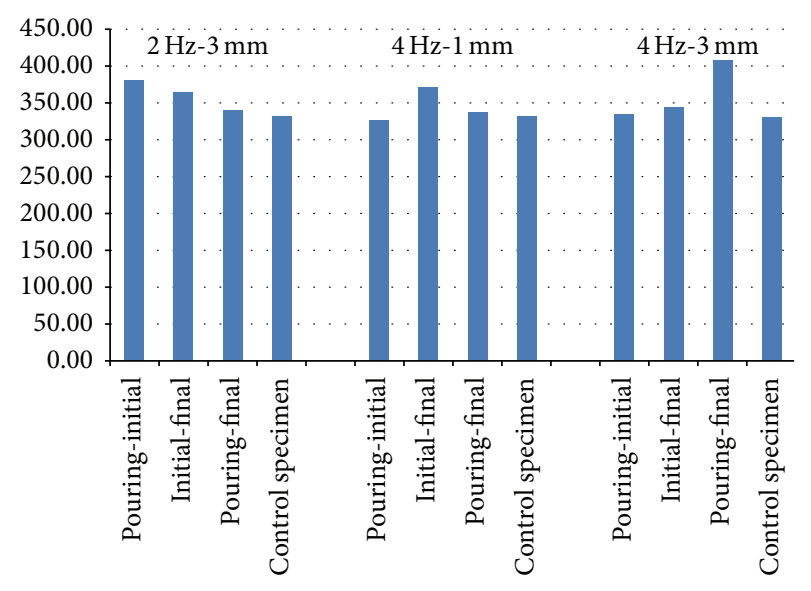

FIGURE 9: HPC electric flux and change ratio $(C)$.

Table 5 and Figure 9 reveal that vibrations with different vibration parameters do not yield a distinct impact on the electric flux of HPC. Compared with the still experiment group, the vibration group yielded a maximum increase of $5.6 \%$ in the electric flux. As shown in Table 6, different vibrations with different parameters yield an insignificant impact on the condensation and antifreeze and thawing performance of concrete. For the 300-time freeze-thaw conditions, the 
TABle 6: Freeze-thaw cycles with 300 dynamic modulus and change ratio.

\begin{tabular}{|c|c|c|c|c|c|c|c|}
\hline $\begin{array}{l}\text { Vibration } \\
\text { parameters }\end{array}$ & $\begin{array}{l}\text { Control } \\
\text { specimen }\end{array}$ & $\begin{array}{l}\text { Pouring-initial } \\
\text { hardening }\end{array}$ & $\begin{array}{c}\text { Changes } \\
\text { proportion/\% }\end{array}$ & $\begin{array}{c}\text { Initial } \\
\text { hardening-final } \\
\text { hardening }\end{array}$ & $\begin{array}{c}\text { Changes } \\
\text { proportion/\% }\end{array}$ & $\begin{array}{l}\text { Pouring-final } \\
\text { hardening }\end{array}$ & $\begin{array}{c}\text { Changes } \\
\text { proportion/\% }\end{array}$ \\
\hline $\begin{array}{l}F=2 \mathrm{~Hz} \\
H=3 \mathrm{~mm}\end{array}$ & 62.5 & 60.5 & -3.2 & 63.1 & +1.0 & 62.2 & -0.5 \\
\hline $\begin{array}{l}F=4 \mathrm{~Hz} \\
H=3 \mathrm{~mm}\end{array}$ & 62.5 & 61.4 & -1.8 & 63.3 & +1.3 & 62.2 & -0.5 \\
\hline $\begin{array}{l}F=4 \mathrm{~Hz} \\
H=1 \mathrm{~mm}\end{array}$ & 62.5 & 63.8 & +2.1 & 61.8 & -1.1 & 62.8 & +0.5 \\
\hline
\end{tabular}

measured dynamic elastic modulus values of various groups did not yield large differences; the dynamic elastic modulus values are in the range of $-3.2 \sim+2.1 \%$. These results indicate that, due to the self-repair effect of the concrete's late-phase hydration reaction, the vibration had an insignificant impact on the durability of the repairing HPC; thus, the impact can be disregarded. The experimental results are consistent with the rules of impact of vibration on the late-phase compressive strength of HPC (e.g., $28 \mathrm{~d}$ compressive strength).

\section{Conclusions}

To examine the rapid repair of highway bridge deck pavement under the condition in which the bridge is open to traffic, this study adopted an electromagnetic test stand to simulate traffic-induced bridge vibration. By analyzing the impact on the compressive strength and durability of HPC, the following conclusions were obtained.

(1) With the action of two simple harmonic vibrations with $2 \mathrm{~Hz}, 3 \mathrm{~mm}$ amplitude, and $4 \mathrm{~Hz}, 3 \mathrm{~mm}$ amplitude, the $1 \mathrm{~d}$ and $2 \mathrm{~d}$ compressive strengths of the HPC specimens decreased significantly, and the maximum reduction rate is $9.1 \%$. As the age of the HPC increased, the HPC continued to undergo a hydration reaction and the fragile components inside the HPC expanded. Therefore, the impact of vibration on the late-phase strength of the HPC specimens was insignificant, which resulted in a loss of strength from $1.4 \%$ to $3 \%$.

(2) The simple harmonic vibration with $4 \mathrm{~Hz}$ and $1 \mathrm{~mm}$ amplitude has a slight effect on the compressive strength of HPC specimens. It is concluded that the amplitude of vibration has a prominent effect on the compressive strength of HPC specimens.

(3) Due to the self-repairing effect of the hydration reaction during the late phase, the vibration had an insignificant impact on the durability of HPC, which can be disregarded. The experimental results are consistent with the vibration impact law for the late-phase compressive strength of HPC.

(4) Based on the experimental results, if the traffic needs to be rapidly restored after bridge deck pavement repairs (e.g., $1 \mathrm{~d}$ or $2 \mathrm{~d}$ after pouring the HPC), the implementation of specific prevention measures, such as heavy vehicle and speed restrictions and the installation of a bridge support, is recommended during the bridge deck pavement repair process to reduce the impact of traffic-induced bridge vibration on the early-phase strength of rapid repair HPC.

Under specific simplification conditions, this study experimentally investigated the impact of vibration on the mechanical properties and durability of HPC from a macro point of view. The impact of bridge vibration on the coagulation and hardening of bridge deck pavement repairing HPC is a complex process. To accurately describe and analyze the impact mechanism and rule, comprehensive macroand microexperimental studies on the forced vibration of concrete should be conducted in the future.

\section{Conflict of Interests}

The authors declare that there is no conflict of interests regarding the publication of this paper.

\section{Acknowledgment}

The work was supported by the Chinese Science and Technology Support Program (Project no. 2012BAG05B01), Hebei Province Talent Project funding support research training (Y2012036), and Young Talents in Hebei support program.

\section{References}

[1] J. R. Zheng, Y. F. Xu, and W. S. Xu, "The study of second vibration impact on concrete strength," Journal of Wuhan Urban Construction Institute, vol. 21, no. 3, pp. 69-72, 2004.

[2] J. J. Wei, J. X. Xing, and Z. Fu, “The impact of traffic-induced bridge vibration on repairing HPC," Journal of Southeast University, vol. 40, no. 5, pp. 1057-1060, 2010.

[3] J. J. Wei, J. X. Xing, and J. C. Xu, "The impact of Vibration on early concrete tensile properties," Journal of Highway and Transportation Research and Development, vol. 01, 2011.

[4] Y. R. Zhang, Y. J. Zhang, and X. Zhang, "The study of disturbance resistance ability of hardening concrete," China Concrete and Cement Products, vol. 10, no. 5, pp. 1-2, 2009.

[5] Y. R. Zhang, Y. J. Zhang, and X. Zhang, "Three techniques to improve disturbance resistance of concrete," Journal of Building Materials, no. 1, pp. 26-29, 2011.

[6] Y. R. Zhang, Y. J. Zhang, and X. Zhang, The Study of Disturbance Resistance Ability of Concrete for Bridge Deck Pavement Repairs, 
vol. 5, Shanghai J \& W Building Material, Shanghai, China, 2009.

[7] M. R. Dunham, A. S. Rush, and J. H. Hanson, "Effects of induced vibrations on early age concrete," Journal of Performance of Constructed Facilities, vol. 21, no. 3, pp. 179-184, 2007.

[8] H. L. Furr and F. H. Fouad, "Effect of moving traffic on fresh concrete during bridge-deck widening," Transportation Research Record, no. 860, pp. 28-36, 1982.

[9] M. R. Dunham and A. S. Rush, "Parametric analysis of the effects of induced vibrations on concrete at early ages," Tech. Rep. 04/A01, Engineering Forensics Research Institute (EFRI), 2004.

[10] A. J. Hulshizer, "Acceptable shock and vibration limits for freshly placed and maturing concrete," ACI Materials Journal, vol. 93, no. 6, pp. 524-533, 1996.

[11] H. K. Hilsdorf and J. L. Lott, "Revibration of retarded concrete for continuous bridge decks," NCHRP Report 106, Highway Research Board, National Academy of Sciences, Washington, DC, USA, 1970.

[12] J. P. Lu, K. R. Ke, and T. C. Lu, "Impact of vibration on curing concrete," Journal of the China Concrete and Cement Products, vol. 5, pp. 15-17, 1991.

[13] D. G. Manning, "Effects of traffic-induced vibrations on bridge-deck repairs," National Cooperative Highway Research Program Synthesis of Highway Practice 86, Transportation Research Board. National Academy of Sciences, Washington, DC, USA, 1981

[14] R. S. Cheng and Z. F. Hu, "Highway bridge load test," Journal of People's Communications Press, vol. 5, pp. 60-67, 2003.

[15] JTG E30-2005, Test Methods of Cement and Concrete for Highway Engineering, China Communications Press. S., 2005. 

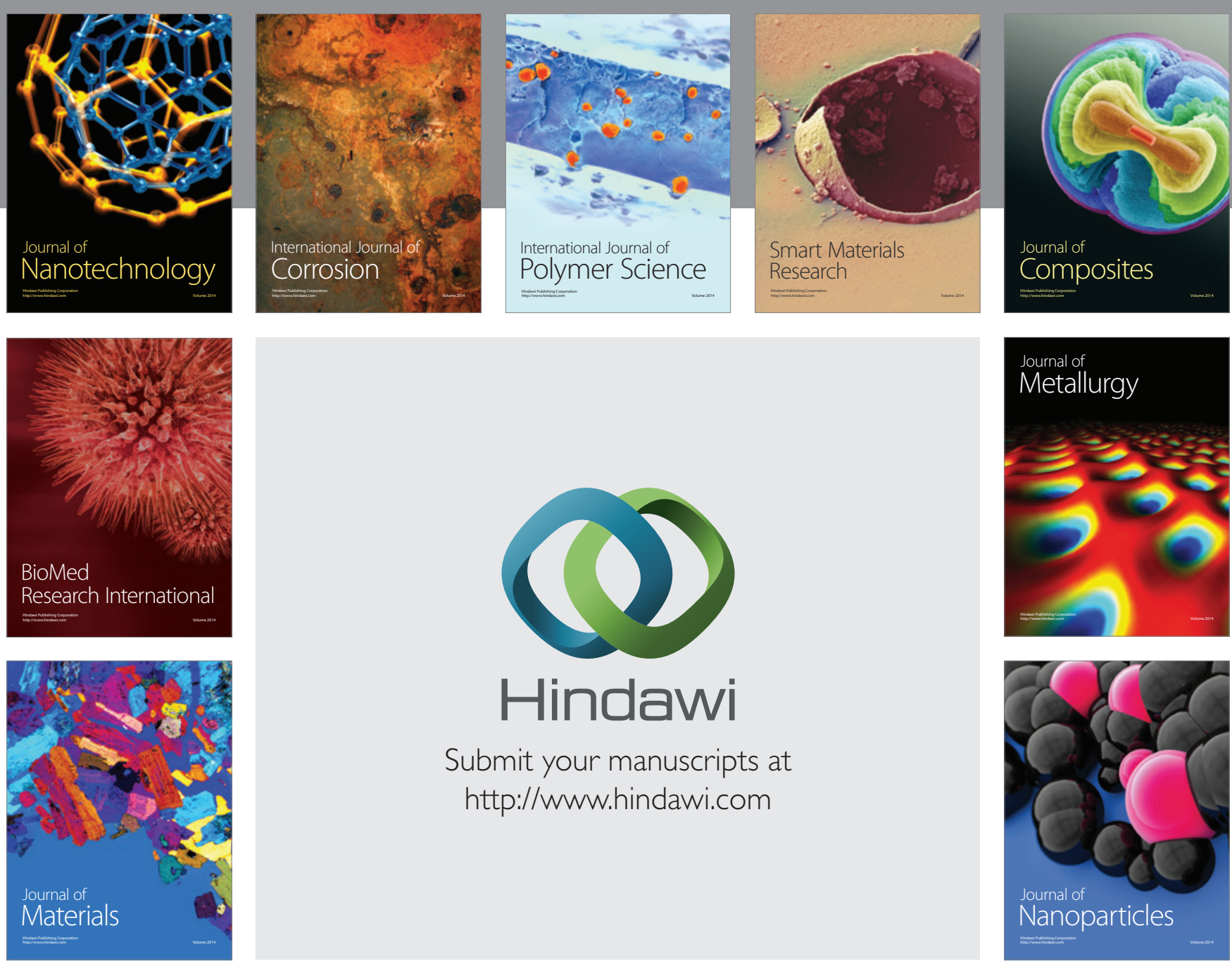

Submit your manuscripts at http://www.hindawi.com
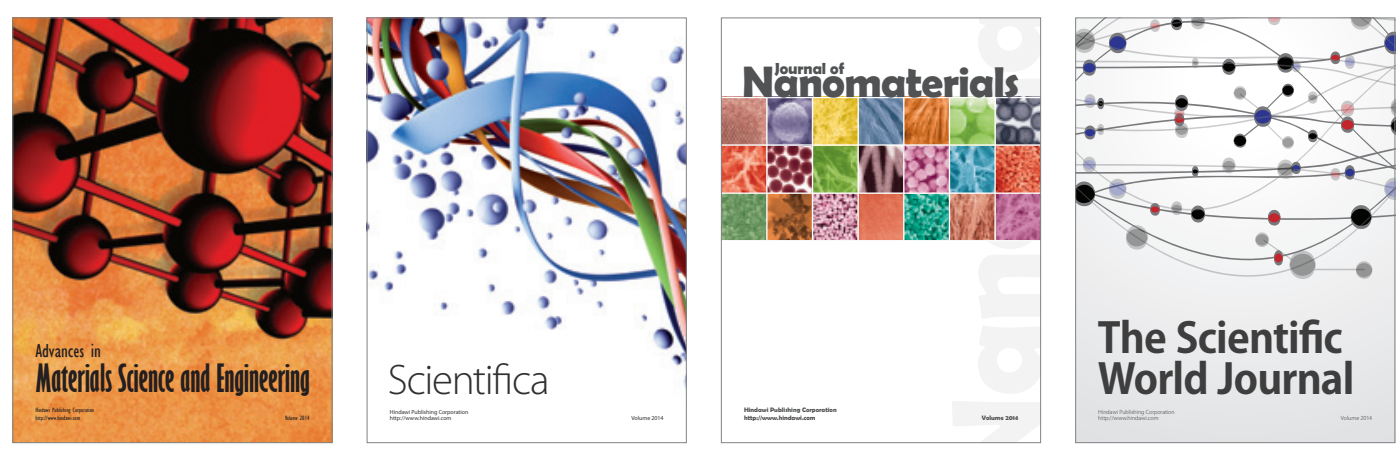

\section{The Scientific World Journal}
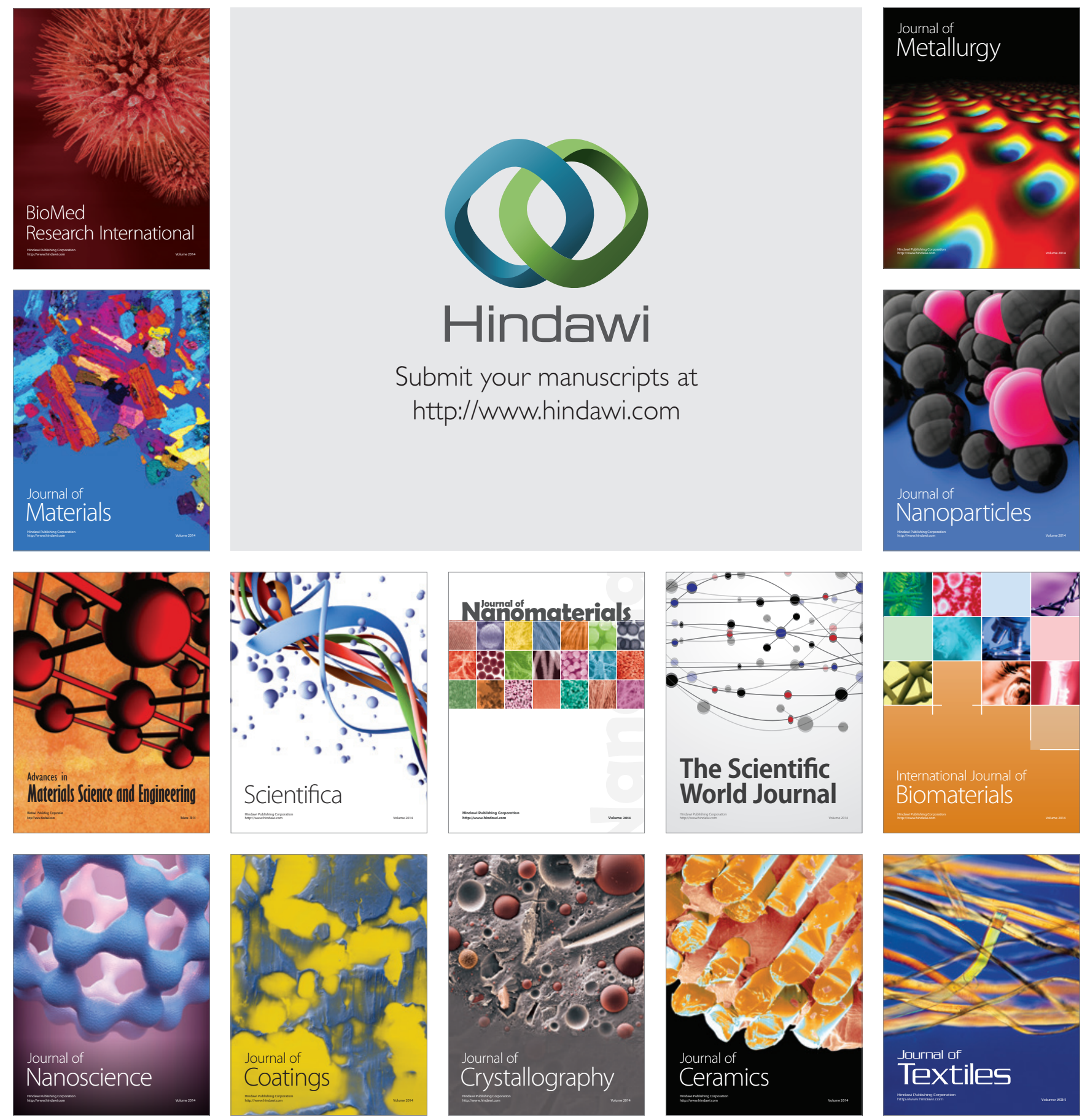